\title{
Proteomic Identification of Binding Partners for the Brain Metabolite Lanthionine Ketimine (LK) and Documentation of LK Effects on Microglia and Motoneuron Cell Cultures
}

\author{
Kenneth Hensley, ${ }^{1}$ Alexandar Christov, ${ }^{1}$ Shekhar Kamat, ${ }^{1}$ X. Cai Zhang, ${ }^{1}$ Kenneth W. Jackson, ${ }^{2}$ Stephen Snow, ${ }^{2}$ \\ and Jan Post ${ }^{3}$ \\ ${ }^{1}$ Oklahoma Medical Research Foundation, Oklahoma City, Oklahoma 73104, ${ }^{2}$ University of Oklahoma Health Science Center, Molecular Resource Core \\ Facility, Oklahoma City, Oklahoma 73118, and ${ }^{3}$ Oklahoma School for Science and Mathematics, Oklahoma City, Oklahoma 73118
}

\begin{abstract}
Lanthionine ketimine (LK) represents a poorly understood class of thioethers present in mammalian CNS. Previous work has indicated high-affinity interaction of LK with synaptosomal membrane protein(s), but neither LK binding partners nor specific bioactivities have been reported. In this study, LK was chemically synthesized and used as an affinity agent to capture binding partners from mammalian brain lysate. Liquid chromatography with electrospray ionization-mass spectrometry of electrophoretically separated, LK-bound proteins identified polypeptides implicated in axon remodeling or vesicle trafficking and diseases including Alzheimer's disease and schizophrenia: collapsin response mediator protein-2/dihydropyrimidinase-like protein-2 (CRMP2/DRP2/DPYSL2), myelin basic protein, and syntaxin-binding protein-1 (STXBP1/Munc-18). Also identified was the recently discovered glutathione-binding protein lanthionine synthetase-like protein-1. Functional consequences of LK:CRMP2 interactions were probed through immunoprecipitation studies using brain lysate wherein LK was found to increase CRMP2 coprecipitation with its partner neurofibromin-1 but decreased CRMP2 coprecipitation with $\beta$-tubulin. Functional studies of NSC-34 motor neuron-like cells indicated that a cell-permeable LK-ester, LKE, was nontoxic and protective against oxidative challenge with $\mathrm{H}_{2} \mathrm{O}_{2}$. LKE-treated NSC-34 cells significantly increased neurite number and length in a serum concentration-dependent manner, consistent with a CRMP2 interaction. Finally, LKE antagonized the activation of EOC-20 microglia by inflammogens. The results are discussed with reference to possible biochemical origins, paracrine functions, neurological significance, and pharmacological potential of lanthionyl compounds.
\end{abstract}

\section{Introduction}

The mammalian brain contains a variety of amino acyl-derived, cyclic thioethers typified by lanthionine ketimine (LK) $(2 H-1,4-$ thiazine-5,6-dihydro-3,5-dicarboxylic acid) (Fig. 1), its cystathionine analog, and derivatives. These compounds, which currently are of unknown function, are formed through alternative reactions of the transsulfuration pathway (Braunstein and Goryachenkova, 1984; Cooper and Anders, 1990; Cavallini et al., 1991; Cooper, 2004), followed by transamination of the resulting linear thioether by glutamine transaminase $\mathrm{K}$ (GTK) (also known as KAT1) with a suitable $\alpha$-keto acid acceptor to generate cyclic imino thioethers

Received 0ct. 22, 2009; revised Dec. 16, 2009; accepted Dec. 24, 2009.

This work was supported in part by the Oklahoma Center for Advancement of Science and Technology, National Institutes of Health Grant NSO44154, the Hereditary Disease Foundation, and the Jean and Judith Pape Adams Charitable Foundation. Bovine tissue used in this study was graciously provided by Dr. Jerry Richey (Oklahoma State University, Department of Veterinary Medicine, Stillwater, OK). We thank Dr. Yasvir Tesiram (Oklahoma Medical Research Foundation, Oklahoma City, OK) and Dr. Susan Nimmo (University of Oklahoma, Department of Chemistry, Stillwater, OK) for assistance in NMR characterizations. We thank Dr. Neil Cashman (University of Toronto, Ontario, (anada) for his generous gift of NSC-34 cultures.

K.H. is the inventor on a pending United States patent relating to lanthionine derivatives used in this work (United States Patent and Trademark Office 20070197515).

Correspondence should be addressed to Dr. Kenneth Hensley at his present address: Departments of Pathology and Neurosciences, MS 1090, University of Toledo Health Science Center, 3000 Arlington Avenue, Toledo, $\mathrm{OH} 43614$. E-mail: kenneth.hensley@utoledo.edu.

DOI:10.1523/JNEUROSCI.5247-09.2010

Copyright $\odot 2010$ the authors $\quad 0270-6474 / 10 / 302979-10 \$ 15.00 / 0$
(Cooper, 2004; Cooper and Anders, 1990; Cavallini et al., 1991) (Fig. 1). Despite its lack of known function, LK exists in mammalian brain at levels of $1-3 \mathrm{nmol} / \mathrm{g}$ tissue (Cavallini et al., 1983; Ricci et al., 1989), a similar magnitude to that of other biochemically important sulfurous metabolites such as homocysteine (hCys) (Broch and Ueland, 1984) and S-adenosyl-hCys (Gharib et al., 1982). Thus, lanthionyl compounds could serve neurochemical function(s) through molecular interactions yet to be elucidated. The origin and function of lanthionine (Lan) and LK were considered in studies from the Cavallini laboratory in the 1980s-1990s (Cavallini et al., 1983, 1991; Fontana et al., 1990; Fontana et al., 1997; Duprè et al., 2000). Cavallini reported that $\left[{ }^{35} \mathrm{~S}\right]$ LK bound syntaptosomal membranes with $60 \mathrm{~nm}$ affinity (Fontana et al., 1990) but did not document bioactivities of LK. To date, no candidate protein(s) responsible for LK binding have been identified, and no bioactivities of LK have been reported.

The present study used a proteomics strategy to identify candidate protein binding partners of LK, in hope of elucidating biological or pharmacological functions inherent to lanthionyl metabolites. An affinity matrix was devised using the Mannich coupling reaction to tether LK to an agarose support (Husi and Grant, 2001). Notable bovine brain proteins that specifically bound the LK-derivatized matrix included lanthionine synthetase C-like protein-1 (LanCL1), a recently discovered glutathione (GSH)-binding protein of unknown function (Chung et 
al., 2007; Zhang et al., 2009), and collapsin response mediator protein-2/dihydropyrimidinase-like protein-2 (CRMP2/DRP2/ DPYSL2), a cytoskeleton structure-regulating protein whose expression, oxidation, or posttranslational modifications have been associated with neurological diseases, including Alzheimer's disease (AD) (Charrier et al., 2003; Arimura et al., 2004; Quach et al., 2004; Cole et al., 2007; Owen et al., 2009) and schizophrenia (Nakata et al., 2003).

The functional implications of LK interactions were explored ex vivo in mouse brain preparations and using cell culture systems in conjunction with a synthetic cell-permeating LK ester. Ex vivo, LK increased or decreased interaction of CRMP2 with protein binding partners $\beta$-tubulin and neurofibromin-1 (NF1) in a partnerspecific manner. ( $R$ )-LK-5-ethyl ester (LKE) elicited subtle but significant morphological alterations in the NSC-34 cells, increasing the number and length of neurites at nonlimiting concentrations of ambient serum. Additional microglia-antagonizing actions of LK were observed. These effects would be consistent with functional interactions between LK and cytoskeleton structureregulating adaptor proteins, including CRMP2, and could prove relevant to the pathophysiology of, as well as pharmacological interventions against, certain neurological conditions.

\section{Materials and Methods}

Synthesis of LK or LKE and Mannich coupling. (R)-LK was synthesized from 3-bromopyruvate and L-cysteine hydrochloride (Alfa Aesar) as described by Cavallini et al. (1983) (Fig. 1). LKE was similarly synthesized using L-cysteine ethyl ester (Alfa Aesar) in $\sim 60 \%$ final yield. Product purity and identity was confirmed by HPLC, ${ }^{1} \mathrm{H}-\mathrm{NMR},{ }^{13} \mathrm{C}-\mathrm{NMR}$, and mass spectrometry (supplemental Figs. 1, 2, available at www.jneurosci. org as supplemental material). LK and LKE were chromatographed by isocratic reverse-phase HPLC across a C18 column with in-line photodiode array and electrochemical detection using a boron-doped diamond electrode (ESA) operating at $1.2 \mathrm{~V}$. The mobile phase was $3 \%$ acetonitrile in $50 \mathrm{~mm}$ lithium acetate, $\mathrm{pH} 5.6$, running at $0.5 \mathrm{ml} / \mathrm{min}$.

LK was coupled to a diaminodipropyl amine (DADPA) agarose matrix using a commercially available kit (PharmaLink; Pierce) according to the instructions of the manufacturer. Briefly, columns were equilibrated in 0.1 м 2-(N-morpholino)ethanesulfonic acid coupling buffer, $\mathrm{pH}$ 4.7. LK was dissolved to $10 \mathrm{~mm}$ in coupling buffer to which was added $2.3 \%$ formaldehyde. The solution was applied immediately to the DADPA column and allowed to react at room temperature overnight. The column was washed thoroughly in $100 \mathrm{~mm}$ sodium citrate, $0.1 \mathrm{~N} \mathrm{NaCl}, 20$ mM HEPES, and 0.2\% 3-[(3-cholamidopropyl)dimethylammonio]-1propanesulfonate (CHAPS) running buffer, $\mathrm{pH} 7.4$, to produce an "LKbaited" column. Citrate was used to minimize nonspecific ion-exchange interactions between low pI proteins and the underivatized DADPA amines. A mock-derivatized or "unbaited" column was created by similar treatment, omitting the dissolved LK component during the coupling incubation period.

Brain lysate preparation and use. Bovine brain was obtained from the Oklahoma State University Veterinary Diagnostic Laboratory. Animals had no clinical signs of brain disease, and the tissue was grossly normal.
One hundred grams of cerebral cortex was homogenized with $500 \mathrm{ml}$ of running buffer containing 1:500 diluted mammalian protease inhibitor cocktail (Sigma). Crude homogenate was centrifuged twice for $15 \mathrm{~min}$ at $10,000 \times g$ and $4^{\circ} \mathrm{C}$. The supernatant was adjusted to $10 \mathrm{mg} / \mathrm{ml}$ protein. One half of the protein solution was passed over the LK-baited column, using gravity-feed flow at $\sim 0.25 \mathrm{ml} / \mathrm{min}$. The other half of the lysate was passed over the unbaited column. Each column was washed with 20 column volumes of running buffer and then eluted with the same buffer containing $100 \mathrm{~mm}$ LK. Eluate was collected in two-column-volume fractions. Protein-containing fractions were pooled and then concentrated five times using $10 \mathrm{kDa}$ MWCO iCON centrifugal concentrating tubes (Pierce). Smaller-scale experiments were performed for purposes of reproduction wherein LK-agarose or mock-treated beads were incubated overnight with smaller volumes of brain lysate, and then centrifuged, washed, and immunoblotted.

Proteomics. Gel bands were stained with colloidal Coomassie Blue (Biosafe; Pierce), excised, and destained in 50\% acetonitrile plus $50 \mathrm{~mm}$ aqueous $\mathrm{NH}_{4} \mathrm{HCO}_{3}$. Tryptic digestion was executed using an in-gel digestion kit (Pierce) according to the instructions of the manufacturer, after reductive alkylation. Briefly, destained gel slices were incubated in $50 \mathrm{~mm}$ tris[2-carboxyethyl]phosphine (TCEP) in $25 \mathrm{~mm} \mathrm{NH}_{4} \mathrm{HCO}_{3}$ for $60 \mathrm{~min}$ at $60^{\circ} \mathrm{C}$. The TCEP solution was discarded, and the sample was incubated with $100 \mathrm{~mm}$ iodoacetamide in $25 \mathrm{~mm} \mathrm{NH}_{4} \mathrm{HCO}_{3}$ for 60 min at ambient temperature in the dark. Samples were rinsed with $25 \mathrm{~mm}$ destaining solution, shrunk in $100 \%$ acetonitrile, and dried at ambient temperature. Dried gel samples were rehydrated with trypsin $(10 \mathrm{ng} / \mathrm{ml})$ in $25 \mathrm{~mm} \mathrm{NH}_{4} \mathrm{HCO}_{3}$. Samples were briefly dried by vacuum centrifugation, and then they were dissolved in $15 \%$ acetic acid/water. Samples were analyzed by liquid chromatography-tandem mass spectrometry (LC-MS/MS) on a Dionex Ultimate 3000 HPLC system equipped with a PepMap100 C18 column of dimensions of 75 micron inner diameter $\times$ $15 \mathrm{~cm}$ length. Gradient elution was performed at $200 \mathrm{nl} / \mathrm{min}$ that con- 
A

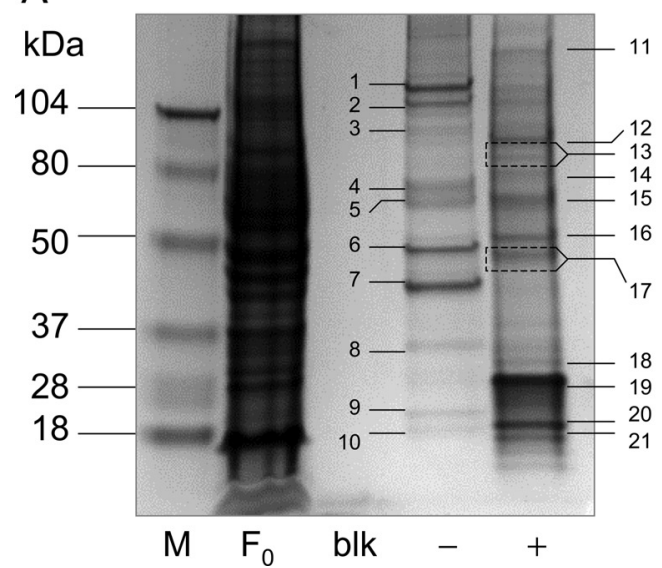

B

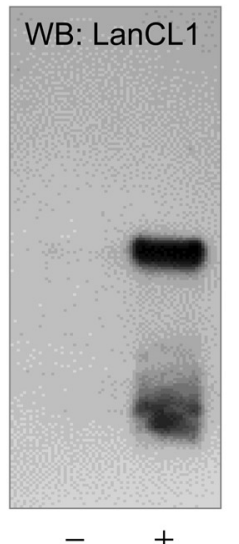

$+$

Figure 2. $\quad A$, Coomassie Blue-stained SDS-PAGE profile of bovine brain proteins captured and released from an LK-derivatized (baited) DADPA column or an unbaited, mock-derivatized column. M, Molecular weight markers; $\mathrm{F}_{0}, 20 \mu \mathrm{g}$ of bovine brain lysate before affinity chromatography; Blk, last column volume of wash (running) buffer before LK elution; - and +, protein fractions eluted with $100 \mathrm{~mm}$ LK from the unbaited and baited columns, respectively. Numbers adjacent to bands indicate proteins that were subjected to tryptic digestion, extraction, and mass spectrometry. Protein identities of these bands are indicated in Table 1. $\boldsymbol{B}, \boldsymbol{C}$, The + and - protein fractions were immunoblotted using antibodies against LanCL1 or DRP2/CRMP2 as an orthogonal method of MS corroboration. WB, Western blot.

sisted of three linear segments of $2-10 \%$ solvent B in 1 min, $10-35 \%$ solvent B in $45 \mathrm{~min}$, and $35-70 \%$ solvent B in $10 \mathrm{~min}$. Solvent A was $0.01 \%$ trifluoroacetic acid (TFA), $0.09 \%$ formic acid, $2 \%$ acetonitrile, and $97.9 \%$ water, whereas solvent B was $0.0085 \%$ TFA, $0.09 \%$ formic acid, $95 \%$ acetonitrile, and $4.9 \%$ water. The column effluent was directed to a nano-electrospray ion source of a QStar Elite Quad-TOF mass spectrometer (Applied Biosystems), which was set to scan from 300 to 2500 mass/charge ratio $(\mathrm{m} / \mathrm{z})$ mass range operated in the positive ion mode for MS and from 50-2400 m/z mass range for MS/MS data. The instrument was operated using Analyst QS 2.0 software in the data-dependent acquisition mode. Data were analyzed by use of the Mascot search engine (software version 2.2), searching the National Center for Biotechnology Rodent protein database on an in-house server (NCBInr 20081216) with a mass tolerance of $\pm 0.1 \mathrm{Da}$ for both MS and MS/MS ions.

Immunochemistry. A rabbit polyclonal antibody against an internal sequence of LanCL1 (LQQMERGLKSADPRDGTG) was produced as reported previously (Chung et al., 2007). A commercial polyclonal antiDRP2/CRMP2 (AB2918) was purchased from Millipore Bioscience Research Reagents. Samples were mixed 1:1 with loading dye (50\% glycerol, $10 \%$ Tris, $0.01 \%$ bromophenol blue, and $2 \% \beta$-mercaptoethanol) and electrophoresed across $4-20 \%$ gradient polyacrylamide gels. Gels were blotted onto polyvinylidene difluoride membranes, blocked overnight in $4 \%$ BSA, and then probed with anti-LanCL1 at 1:1000 dilution. For immunoprecipitation (IP) experiments, adult C57B6 mouse whole brains were lysed in $20 \mathrm{~mm}$ HEPES, $10 \mathrm{~mm} \mathrm{NaCl}$, and $0.2 \%$ CHAPS plus mammalian protease inhibitor cocktail (Sigma) and centrifuged to pellet debris, and supernatants were adjusted to $3 \mathrm{mg} / \mathrm{ml}$. The suspensions were divided in two, each half receiving $5 \mathrm{~mm}$ LK and the other receiving vehicle (saline) only. After $2 \mathrm{~h}$ of gentle agitation at $4^{\circ} \mathrm{C}$, protein suspensions were immunoprecipitated using the anti-CRMP2 and reagents from Pierce Classic mammalian IP kit. Proteins were blotted as described above, under nonreducing conditions to minimize IgG heavy-chain interference with $\beta$-tubulin signals, and blots were probed with monoclonal anti- $\beta$-tubulin (Millipore Bioscience Research Reagents clone KMX-1) or polyclonal anti-neurofibromin-1 (AB17963; Abcam).

NSC-34 cells. NSC-34 cells are a motor neuron-like line derived from the fusion of mouse embryonic motor neurons with a neuroblastoma cell line (Durham et al., 1993). NSC-34 cells display neuronal morphology with neuritic extension in response to growth factors (Durham et al., 1993; this study). NSC-34 cells were obtained as a gift from Dr. Neil Cashman (University of Toronto, Ontario, Canada). Cells were cultured in DMEM containing $1000 \mathrm{U} / \mathrm{ml}$ penicillin plus $1000 \mathrm{mg} / \mu \mathrm{l}$ streptomy-

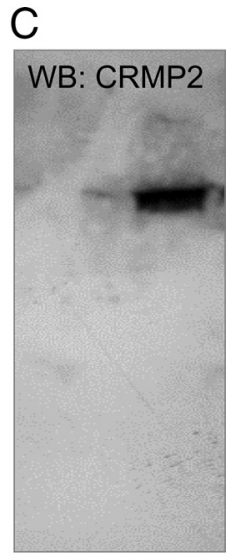

$+$ cin and supplemented with $10 \%$ fetal calf serum (FCS). Cells were passaged to $30 \%$ confluence by dilution from fully confluent cultures, into $75 \mathrm{~cm}^{2}$ flasks or six-well plates containing phenol red-free DMEM plus penicillin/streptomycin with variable concentrations of FCS, plus or minus synthetic LKE as described.

At $20 \mathrm{~h}$ after passage, either $10 \mu \mathrm{g} / \mathrm{ml}$ Hoechst 33342 (Invitrogen) or $4 \mu \mathrm{m}$ ethidium homodimer-1 and $2 \mu \mathrm{M}$ calcein acetoxymethylester (LIVE/DEAD Viability/Cytotoxicity kit; Invitrogen) were added to the cells. After $0.5 \mathrm{~h}$ incubation at $37^{\circ} \mathrm{C}$, the samples were photomicrographed on a Nikon TE2000-E inverted epifluorescent microscope. Bright-field, fluorescent, and combined images were recorded from three wells per treatment per experiment, with three to four fields per well and 40-200 cells per field at $20 \times$ magnification. Images were morphometrically assessed using MetaMorph software (Molecular Devices) by a blinded examiner. The number of cells per microscopic field and the cell viability (percentage of total cell number) were counted. The number of neurites (defined as outgrowing processes longer than $15 \%$ of the diameter of the soma) and their measured length in 40-100 individually recognized cells were also quantified. Experiments were independently replicated at least three times. In other experiments, NSC-34 cell viability was monitored by a colorimetric tetrazolium reduction assay using MTS [3-(4,5-dimethylthiazol-2-yl)-5-(3-carboxymethonyphenol)2-(4-sulfophenyl)-2 Htetrazolium, inner salt] (Promega Aqueous OneStep) in accordance with the instructions of the manufacturer.

EOC-20 cells. EOC-20 microglia are cytokine-responsive cells that generate nitric oxide $(\cdot \mathrm{NO})$ in response to challenge with tumor necrosis factor $\alpha(\mathrm{TNF} \alpha)$ or other inflammogens (Walker et al., 1995; Hensley et al., 2003). EOC-20 cells were obtained from American Tissue Culture Collection and cultured in $75 \mathrm{~cm}^{2}$ flasks before subculturing into 24-well plates for experimentation. Cells were maintained in DMEM supplemented with 10\% FCS and 20\% conditioned medium from L-292 fibroblasts (American Tissue Culture Collection). Recombinant murine TNF $\alpha$ was purchased from Calbiochem and dissolved in $4 \%$ bovine serum albumin (BSA). LKE was dissolved by dilution into cell culture medium $0.5 \mathrm{~h}$ before TNF $\alpha$ challenge. After $24 \mathrm{~h}$ stimulation with 20 $\mathrm{ng} / \mathrm{ml} \mathrm{TNF} \alpha$ or BSA vehicle, in the absence or presence of synthetic LK or LKE, culture medium was removed and assayed for nitrite using the classic Griess assay (Marzinzig et al., 1997) using commercially available diazotization reagents (LabChem). Viability was determined in parallel cultures by tetrazolium reduction.

\section{Results \\ Identification of candidate LK interaction partners by a proteomics approach}

A one-dimensional SDS-PAGE profile of LK-eluted proteins is shown in Figure $2 \mathrm{~A}$. A number of proteins bound nonspecifically to the unbaited, DADPA columns. Preliminary studies indicated these proteins to consist mainly of low pI species, suggesting an ion-exchange interaction with the DADPA column (data not shown). Subsequent experiments minimized this binding by the inclusion of $100 \mathrm{~mm}$ citrate in the running and elution buffers; nonetheless, some proteins appeared to bind the unbaited column in a manner that was releasable with $100 \mathrm{~mm} \mathrm{LK}$ (Fig. 2A, Table 1). These proteins were identified from mass spectrometry of tryptic digests as being generally acidic nucleoproteins with an average estimated pI of $5.6 \pm 1.6 \mathrm{SD}$ (Fig. $2 \mathrm{~A}$, Table 1 ) that likely retained interaction with the basic column even in the presence of 
Table 1. Mass spectrometric identification of proteins eluted from mock- and LK-baited columns

\begin{tabular}{llcc}
\hline Band(s) & Identity & Predicted pl & MOWSE \\
\hline $1,3(-)$ & Nucleolin-related protein-1 (NRP-1) & 4.8 & 129 \\
$2(-)$ & Valosin-containing protein & 5.3 & 745 \\
$4(-)$ & Nucleosome assembly protein-4 (NAP-4) & 5.1 & 249 \\
$5(-)$ & $\beta$-tubulin & 4.9 & 250 \\
$6(-)$ & SET translocation protein & 4.2 & 403 \\
$7(-)$ & Acidic nucleophosphoprotein-2 & 5.1 & 160 \\
$8(-)$ & Casein kinase-II $\beta$ & 5.6 & 136 \\
$9(-)$ & Ribosomal protein L22 & 9.8 & 402 \\
$10(-)$ & Acidic 60S ribosomal protein-2 & 5.9 & 484 \\
$11(+)$ & Complement H factor-1 & 6.8 & 151 \\
$12(+)$ & Heat shock protein-70 (HSP-70) & 5.9 & 403 \\
$13(+)$ & Collapsin response mediator-2 (CRMP2) & 7.3 & 122 \\
& $\quad$ [dihydropyrimidinase-like 2 (DRP2)] & & \\
$14(+)$ & Syntaxin-binding protein-1 (Munc18-1, STXBP1) & 7.0 & 419 \\
$15(+)$ & $\beta$-tubulin & 4.9 & 350 \\
$16(+)$ & $\beta$-actin & 5.6 & 182 \\
$17(+)$ & Lanthionine synthetase-like protein-1 (LanCL1) & 7.8 & 376 \\
$18(+)$ & Myelin proteolipid protein (PLP) & 8.4 & 197 \\
$19-21(+)$ & Myelin basic protein (MBP) & 11.3 & 290 \\
\hline
\end{tabular}

"Band number" refers to protein band annotations in Figure $1 ;(-)$ and $(+)$ indicate elution from unbaited and LK-baited columns, respectively. MOWSE, Molecular weight search.

high citrate; this binding, as expected, would be diminished by the addition of the tricarboxylic citric acid.

Despite the refractory binding of some acidic brain proteins to the unbaited DADPA column, a clearly different set of proteins was found to bind and elute from the LK-baited column (Fig. $2 A)$. These proteins were identified from mass spectrometry of tryptic digests and were found to have generally neutral or even alkaline $\mathrm{pI}$ values with an average estimated pI of 7.6 $\pm 2.1 \mathrm{SD}$ (Fig. 2A, Table 1). Thus, it is likely that these proteins that bound the LK-baited column did so through LK-dependent binding interactions that could be readily competed by elution with free LK and not through a nonspecific ion-exchange interaction with free DADPA- $\mathrm{NH}_{3}{ }^{+}$.

Proteins that bound the LK-baited column but not the control, unbaited column included low-to-moderate copy number proteins involved with cell membrane structure or function (Table 1). These include $\beta$-actin, DRP2/CRMP2, complement $\mathrm{H}$ factor, heat shock protein-70, myelin basic protein (MBP), myelin proteolipid protein, syntaxin binding protein-1 (STXBP1 or Munc-18), and, notably, LanCL1 (Figs. 2A, 3). We previously raised a polyclonal antibody against a defining sequence within LanCL1 (Chung et al., 2007). Therefore, as an orthogonal test of protein identity, equal volumes of eluate from baited and unbaited columns were blotted against anti-LanCL1. The $42 \mathrm{kDa}$ band corresponding to LanCL1 was clearly and specifically immunoreactive in eluates from the LK-baited but not the unbaited column (Fig. 2 B). Similarly, a commercial antibody against DRP2/CRMP2 recognized the appropriate protein band (Fig. 2C).

It is possible that some of the LK:protein interactions documented in this study are mediated through nonphysiologically relevant ionic interactions between highly basic proteins and the acidic LK-baited column, although steps were taken to minimize such artifacts by including high concentrations of the tricarboxylic acid citrate in the working buffers. Any such ion-exchange artifacts would be more suspect for the most basic or acidic proteins that were captured on the LK column and less likely for proteins with estimated pI values nearer to neutrality (e.g., DRP2/CRMP2 and LanCL1) (Table 1).
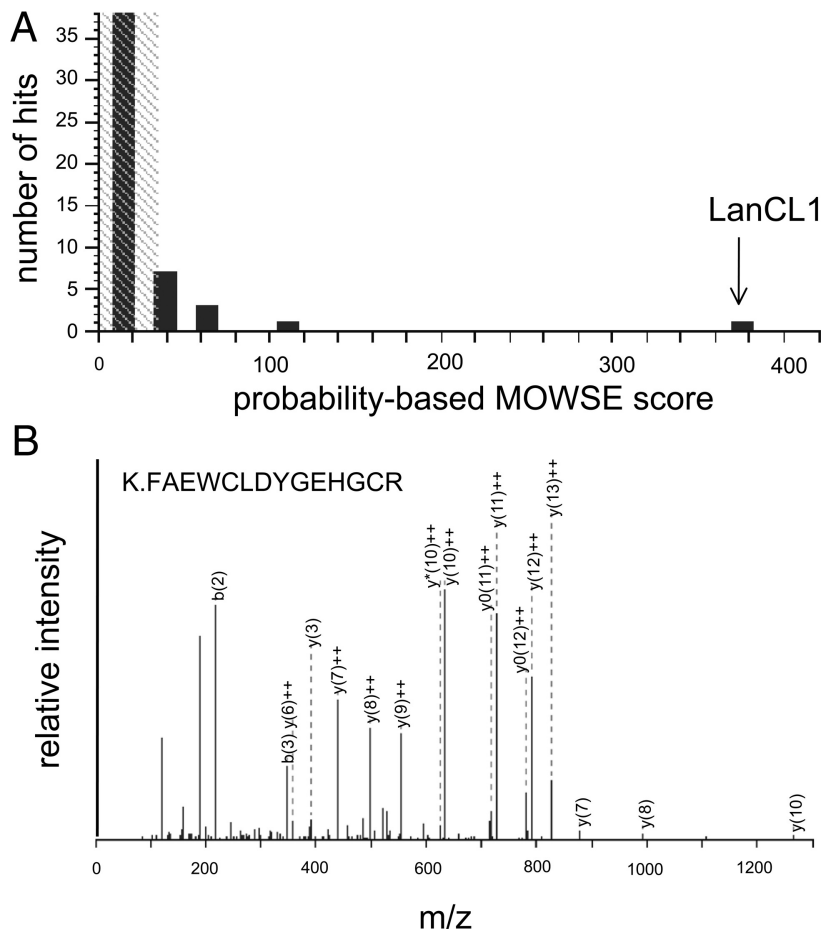

Figure 3. $\quad \boldsymbol{A}$, A molecular weight search probability-based protein identification output; $\boldsymbol{B}$, a representative electrospray ionization-MS/MS of a tryptic peptide derived from in-gel digestion of the Coomassie Blue-stained band identified as LanCL1 in Figure 2.

\section{LK affects CRMP2:protein binding partner interactions ex vivo}

A series of in vitro assays and cell culture experiments were undertaken to ascertain whether LK possesses discrete bioactivities relevant to neuropathology or neuropharmacology. The proteomics observation of LK binding to CRMP2 provided guidelines for initial experiments. As a first step to determine any functional significance of the apparent LK:CRMP2 interaction, a coimmunoprecipitation experiment was conducted to determine whether the presence of LK in brain lysate might measurably affect CRMP2 interactions with known protein binding partners $\beta$-tubulin (Charrier et al., 2003; Arimura et al., 2004; Quach et al., 2004) or neurofibromin-1 (Lin and Hsueh, 2008). Whole-brain mouse lysate was prepared as described in Materials and Methods with or without inclusion of $5 \mathrm{mM}$ LK in the lysis and immunoprecipitation buffers. Anti-CRMP2 immunoprecipitates were blotted against anti-CRMP2, anti- $\beta$-tubulin, or anti-NF1 (Fig. 4). The presence of LK in the lysis and immunoprecipitation buffers markedly decreased the amount of $\beta$-tubulin that was coprecipitated with CRMP2 but increased the amount of NF1 that was coprecipitated (Fig. 4), suggesting functional effects of LK interaction with CRMP2 that are binding partner specific. It is interesting that MBP was identified as a CRMP2 interacting partner (Fig. 5) as well as an LK-binding partner (Fig. 2, discussed above), suggesting that some of the apparent LK-binding partners may actually represent members of extended protein complexes rather than proteins bound directly to LK.

In parallel with the immunoblot analyses, samples of immunoprecipitate were analyzed by LC-MS/MS (Fig. 5). A $50 \mathrm{kDa}$ band sequenced as $\beta$-tubulin clearly was present in $\operatorname{LK}(-)$ samples but much decreased in $\mathrm{LK}(+)$ samples, corroborating the immunoblot observation (Fig. 5). A variety of other cytoskeletal proteins coimmunoprecipitated with CRMP2, including some species that have not been associated previously with CRMP2. 
A

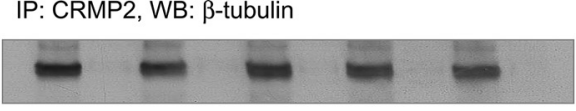

IP: CRMP2, WB: neurofibromin

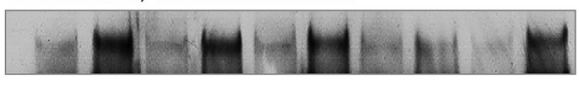

IP: CRMP2, WB: CRMP2

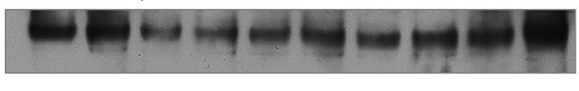

LK

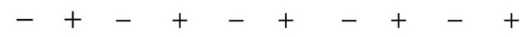

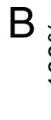

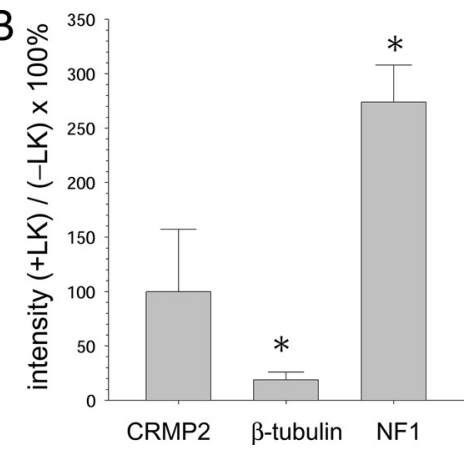

Figure 4. LK affects CRMP2 interaction with known protein binding partners. Whole-brain mouse protein extract was treated with or without $5 \mathrm{~mm}$ LK and immunoprecipitated with anti-CRMP2. A, Immunoprecipitated samples were electrophoresed under nonreducing conditions and blotted with antibodies against NF1 ( 300 kDa), $\beta$-tubulin $(50 \mathrm{kDa})$, or CRMP2 (60 kDa) as indicated. $B$, Bands from the blots in $A$ were quantified by densitometry, and the data were graphed as the value of each LK-treated sample, as a percentage of the mean of the respective samples that were not treated with $L K$. Error bars represent mean $\pm S D ;{ }^{*} p<0.05$ by pairwise $t$ test. WB, Western blot.

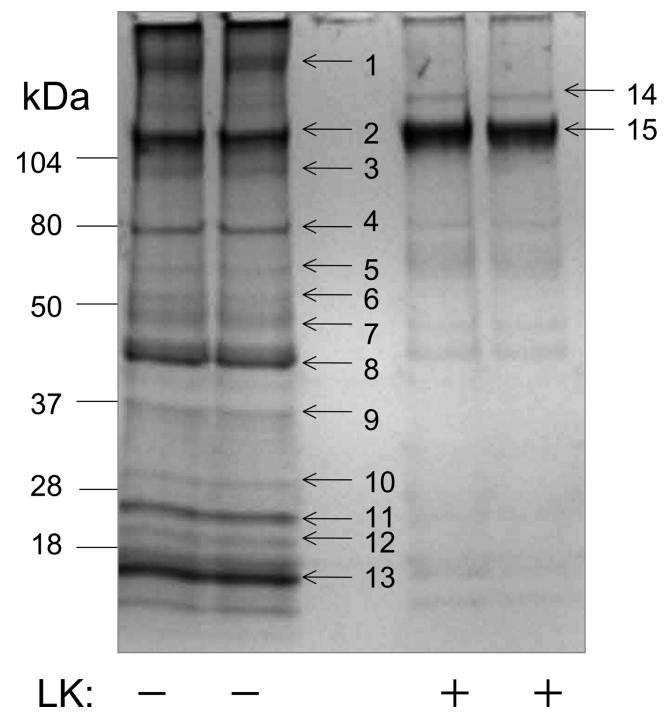

ical saline, $\mathrm{pH}$ 7.4. Diluted aliquots of this reaction were assayed by isocratic HPLC with UV detection. LKE could be quantitatively converted to $\mathrm{LK}$ in vitro under these conditions within $\sim 1$ h (Fig. 6).

After synthesizing LK and LKE, the compounds were evaluated in standard assays for anti-oxidant and anti-inflammatory activity that are extant in the authors' laboratory (Hensley et al., 2003). Accordingly EOC-20 microglia were treated with various concentrations of LK or LKE and then challenged with recombinant TNF $\alpha$, and cellular activation was quantified $24 \mathrm{~h}$ later by measurement of released $\mathrm{NO}_{2}^{-}$ (Hensley et al., 2003). Both LK and LKE inhibited $\mathrm{NO}_{2}^{-}$release with no effect on cell viability (Fig. 7). LKE was significantly more potent than LK, demonstrating significant effects at low micromolar concentrations, consistent with expectations of improved cellular penetrance of the ester over the dicarboxylic acid (Fig. 7). Similar effects of LKE were observed when microglia were treated with bacterial lipopolysaccharide or when RAW264.7 macrophages were used in the assay (data not shown). Direct reaction of LKE with $\cdot \mathrm{NO}$ or $\mathrm{NO}_{2}^{-}$was ruled out by control experiments wherein LKE or LK was incubated $20 \mathrm{~h}$ with $\mathrm{NO}_{2}^{-}$standards or with the nitric oxide releasing agent $S$-nitroso- $N$ acetylpenicillamine (data not shown).

\section{Documentation of neuroprotective and} morphogenic activities of synthetic LK-ester in NSC-34 motor neuron-like cells The finding that CRMP2 is a possible binding partner for LK prompted the question of whether LK might affect CRMP2-dependent processes such as neuritic morphogenesis in neuronal cells. Such effect might be anticipated because CRMP2 mediates microtubule extension versus retraction in a growth factor-sensitive manner (Charrier et al., 2003; Arimura et al., 2004; Quach et

CRMP2-associated proteins that were sequenced as neurofilament light chain, actin, and $\alpha$-internexin neuronal intermediate filament protein decreased with LK, whereas a band corresponding to neurofilament medium chain increased in the presence of LK (Fig. 5). These proteomics data extend the size of the known CRMP2 interactome and further indicate that the LK effect on CRMP2 complexation is interaction partner specific.

\section{LK and its ethyl ester antagonize TNF $\boldsymbol{\alpha}$ activation of EOC-20 microglia}

Dicarboxylic acids resist passage across cell membranes, a limitation that can be circumvented by derivatizing the carboxylates with ethyl groups that can be cleaved through the high ambient activity of cellular esterases (Li et al., 2008). Accordingly, LKE was synthesized as described (Fig. 1). To test for hydrolyzability of the ester and further confirm product identity, a $10 \mathrm{~mm}$ solution of LKE was treated with $20 \mathrm{U} / \mathrm{ml}$ porcine liver esterase in physiolog- al., 2004). In our laboratory, NSC-34 cells are used to discern toxicologic parameters of oxidants and xenobiotics and to investigate effects of paracrine factors on axonal structure and function. These cells display clear neuronal morphology with growth factor-dependent polarization and process extension (Durham et al., 1993). Studies therefore were undertaken to determine whether LKE influenced either the viability or the morphological characteristics of these cells under conditions of oxidative stress or growth factor variation.

In initial experiments, LKE was evaluated merely for cell toxicity or tolerance. NSC-34 cell viability was not affected by $24-48$ $\mathrm{h}$ treatment with LK or LKE alone (data not shown). In contrast, NSC-34 cells exposed to $\mathrm{H}_{2} \mathrm{O}_{2}$ displayed peroxide dose-dependent toxicity as measured by tetrazolium reduction assays (Fig. 8). LKE dose dependently protected the cells from $\mathrm{H}_{2} \mathrm{O}_{2}$ toxicity with almost complete protection at stoichiometric ratios of LKE: $\mathrm{H}_{2} \mathrm{O}_{2}$ (Fig. 8). This might indicate a simple chemical reaction of 

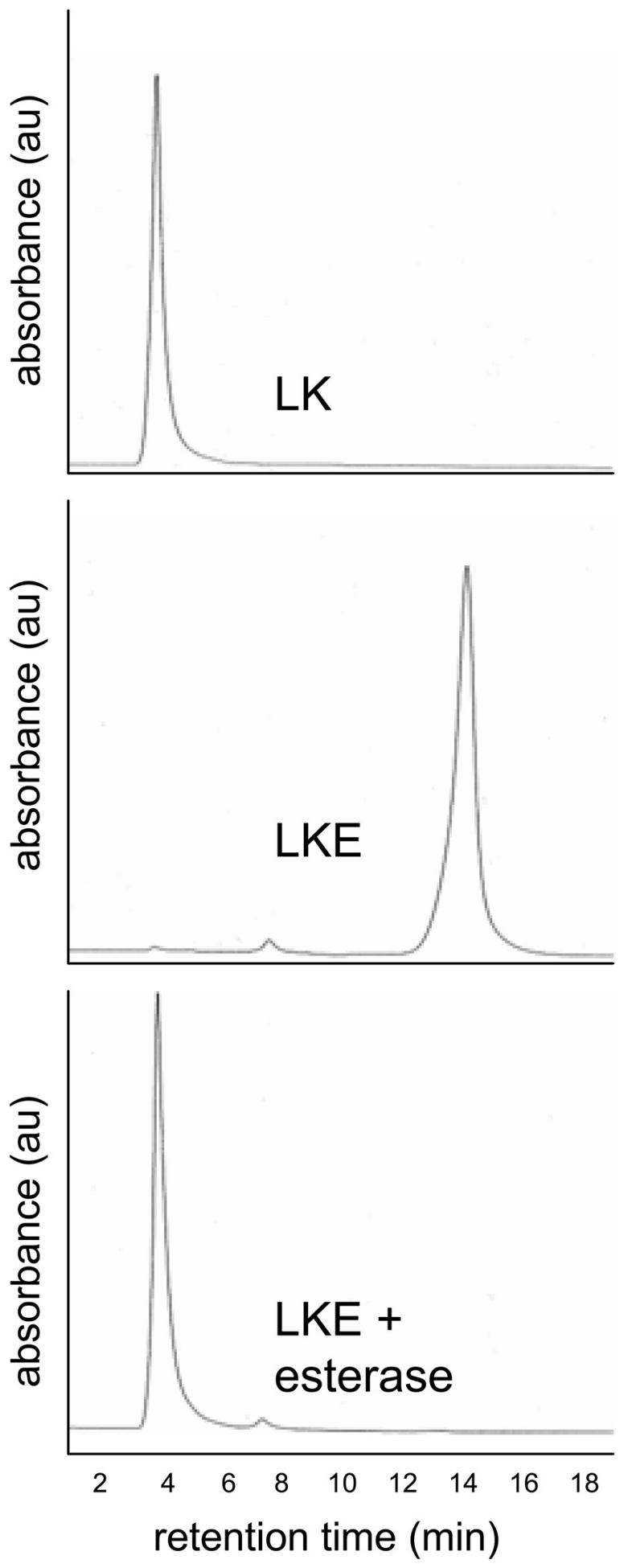

Figure 6. Synthetic LKE is readily hydrolyzed to LK by general esterase activity. Synthetic LKE was treated with porcine esterase as described in Results and analyzed with HPLC with ultraviolet-visible spectrophotometry (UV/Vis) detection to determine whether the enzyme could hydrolyze the compound to yield LK. A peak corresponding to the retention time and UV/Vis characteristics of authentic LK was observed in esterase-treated LKE solutions. au, Arbitrary units.

the sulfide with peroxide, to scavenge the reactive oxygen. There was, however, no indication of cytotoxicity of LKE at any dose tested in either the presence or absence of peroxide stress.

Microscopic observation suggested visible LKE effects on the morphology of the cultured NSC-34 cells, particularly with re-
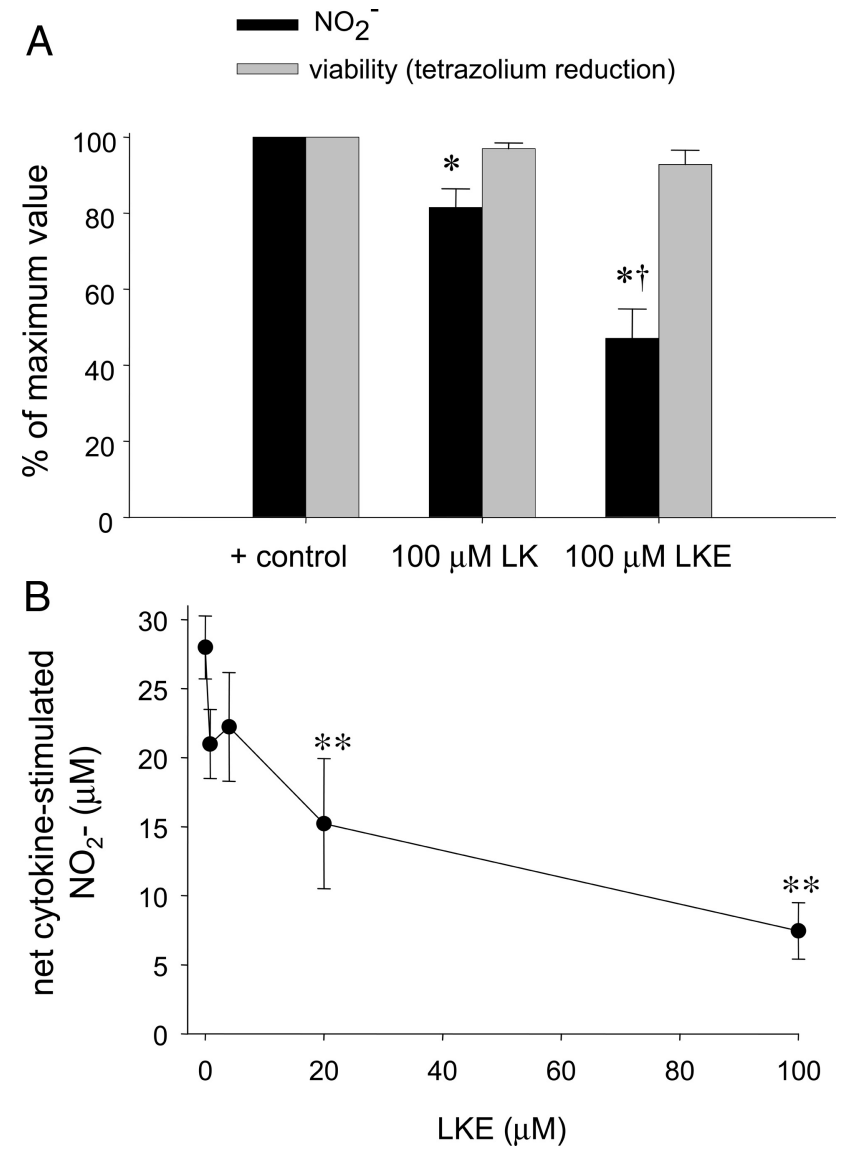

Figure 7. LK and LKE inhibit TNF $\alpha$-stimulated $\cdot N 0$ production in EOC-20 microglia. $A$, Comparison of $L K$ and $L K E$ effects at $100 \mu \mathrm{m}$ of each of the test compounds. $\boldsymbol{B}$, Dose dependency of the LKE suppression of nitrite accumulation in EOC-24 cells challenged with TNF $\alpha .{ }^{*} p<0.05$ relative to positive control (no LK or LKE, cytokine only); ${ }^{* *} p<0.01$ relative to positive control; ${ }^{\dagger} p<0.05$ relative to LK-treated cytokine-stimulated cells. Each error bar represents mean \pm $\operatorname{SEM}(n=6)$; statistical significance determined by unpaired two-tailed $t$ tests.

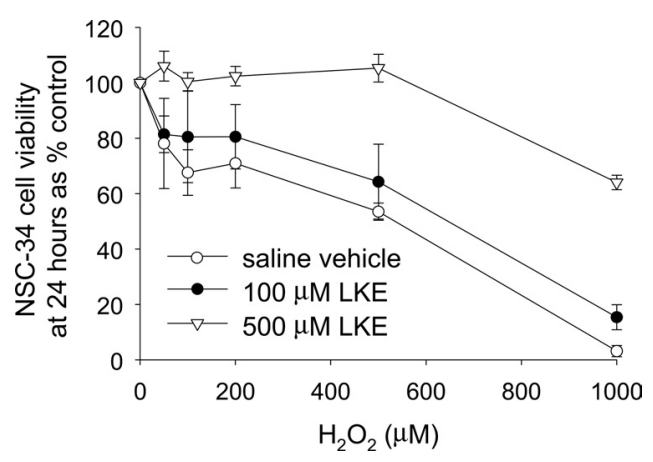

Figure 8. LKE dose dependently protects NSC-34 motor neuron-like cells from toxicity caused by hydrogen peroxide. Cells were treated with the indicated concentrations of $\mathrm{H}_{2} \mathrm{O}_{2}$ in the presence or absence of various doses of $L K E$, and cell viability was determined by tetrazolium reduction $24 \mathrm{~h}$ later. Data represent mean \pm SEM $(n=6)$. Both 100 and $500 \mu \mathrm{M}$ LKE produced statistically significant protection as assessed by repeated-measures ANOVA.

spect to length of neurites in neurite-bearing cells. These initial anecdotal observations prompted additional, objective, quantitative experiments conducted using an approach similar to that of Arimura et al. (2004) and Quach et al. (2004) who studied CRMP2-dependent neurite extension in chicken dorsal root ganglia. According to these researchers, increased CRMP2 expression leads to longer neurites with multiple axons appearing in 

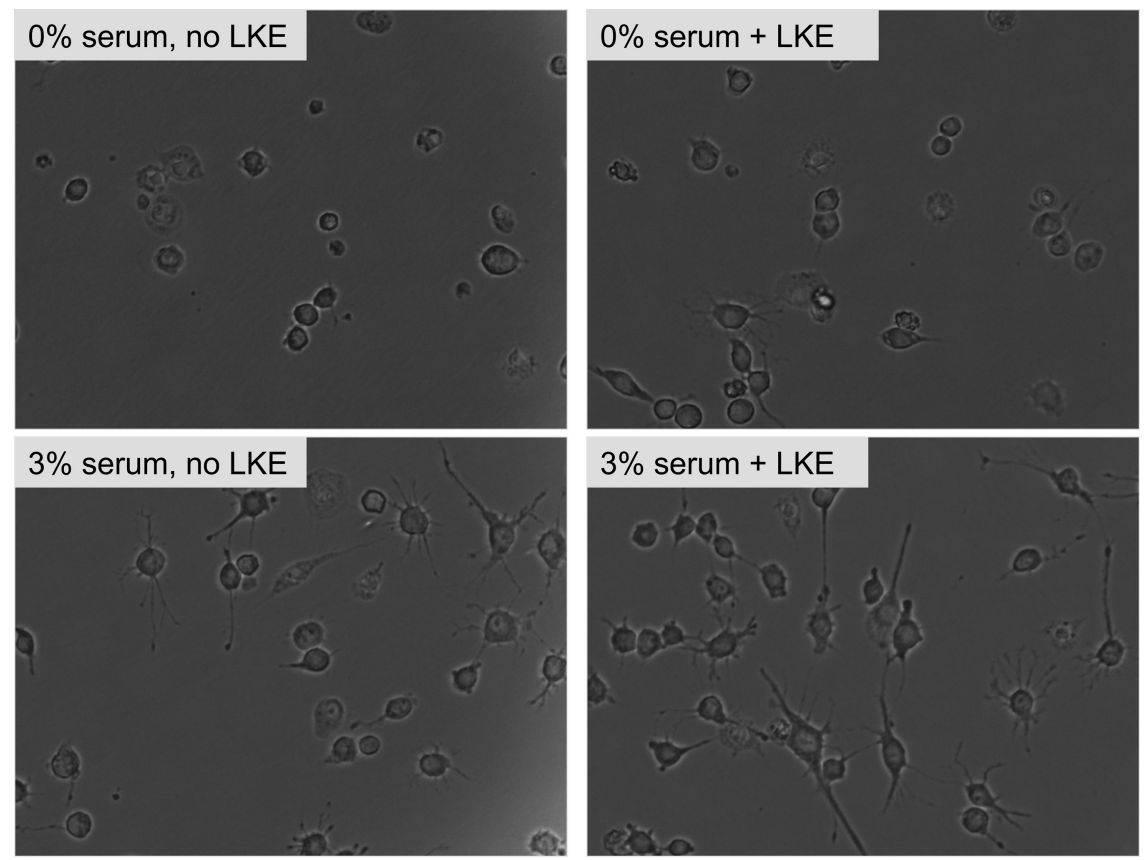

Figure 9. Photomicrographs of NSC-34 cells cultured under different ambient concentrations of FCS and LKE as indicated in each panel label. Images of fluorescently labeled cells were processed with computer-assisted algorithms and quantified for morphometry as described in Results.
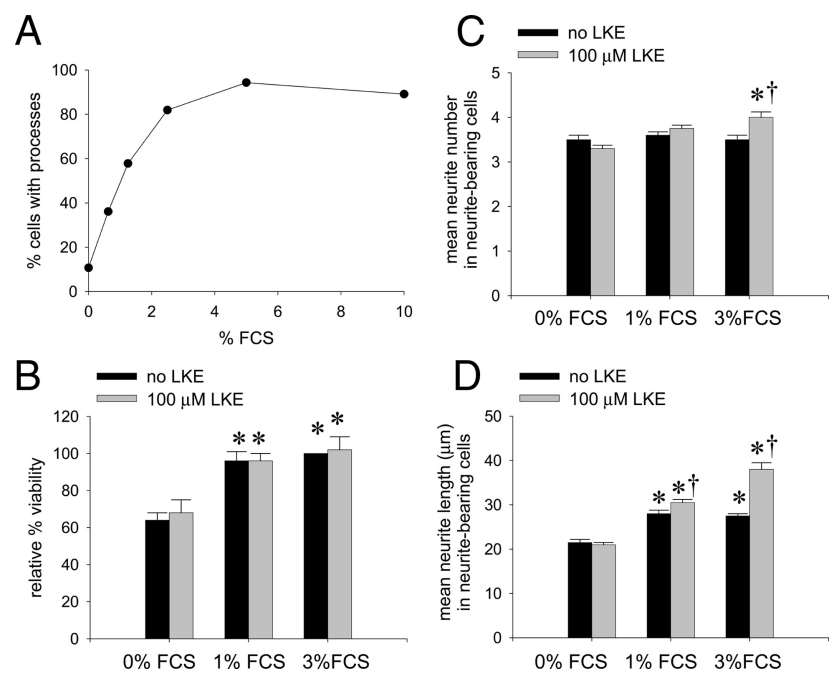

Figure 10. Quantitation of serum concentration and LKE-dependent effects on NSC-34 cell viability and morphological parameters. $A$, Effect of increasing serum on the fraction of NSC-34 cells developing neurites. $\boldsymbol{B}$, Relative viability of NSC-34 cells as indexed by the tetrazolium reduction assay. $\boldsymbol{C}$, Effect of FCS concentration and LKE exposure on the measured average number of neurites per cell. $\boldsymbol{D}$, Effect of FCS concentration and LKE exposure on the average neurite length per cell. Error bars indicate mean \pm SEM of six fields containing 40-100 cells per field in a typical experiment. ${ }^{*} p<0.05$ relative to serum-free condition; ${ }^{\dagger} p<0.05$ for LKE effect, by two-tailed $t$ test.

primary embryonic neuron systems. To begin assessing whether LKE exerts similar morphogenic effects in NSC-34 cells, these cells were passaged at various ambient concentrations of fetal calf serum (FCS) to produce a graded effect on neuritic process extension, which is exquisitely dependent on ambient trophic factors and saturates at higher growth factor concentrations (Quach et al., 2004). LKE was added or omitted at each FCS concentration, and morphology was quantitatively assessed 18-20 h later.
As expected, NSC-34 cells demonstrated an increased propensity to extend neurites with increasing serum in the range of $0-6 \%$ FCS (Figs. 9, 10A). This effect was clearly evidenced by an FCS concentration-dependent increase in the proportion of cells that extended neurites (Fig. 10A) and in the mean total length of neurites in neurite-bearing cells (Fig. $10 D)$. Increasing FCS did not significantly affect the average number of neurites arising from neurite-bearing cells (Fig. 10C). The effect of FCS on cell viability measured by the standard tetrazolium method saturated near $1 \%$ FCS with no significant change in the $1-3 \%$ FCS range (Fig. 10B); however, the morphometric correlates of ambient serum concentration increased significantly from 1 to $3 \%$ FCS (Fig. 10C,D), indicating an effect of FCS components that was not purely ascribable to increased cell survival. When cells were imaged with the live/dead reagents, dead cells were seldom seen $(<5 \%)$ even at $0 \%$ FCS (data not shown), suggesting that part of the difference in apparent viability from $0-1 \%$ FCS during tetrazolium reduction assays might have arisen from differences in metabolic rates between differentiating, FCS-treated versus FCS-untreated cells rather than from differences in the number of living versus dead cells in the two groups.

LKE had no significant effect on the proportion of cells that extended neurites at $0-3 \%$ FCS (data not shown). At 1 and 3\% FCS, LKE-treated NSC-34 cells showed a significant increase in the average length of neuritic processes arising from neuritebearing cells (Fig. 10C). At 3\% FCS, LKE-treated cells also demonstrated a $25 \%$ increase in the average number of neurites per neurite-bearing cell when compared with parallel, LKE-untreated cultures (Fig. 10C). The LKE effect on average neurite length was most noticeable and statistically significant at 3\% FCS but not 1\% FCS (Fig. 10C).

One notable and sometimes striking hallmark of CRMP2 overexpression in primary cell culture is the CRMP2-dependent production of supernumerary axons (Arimura et al., 2004). In immortalized cell lines, the formal definition of an axon based on growth cone formation, expression, and localization of synaptic proteins is not strictly possible. A practical, operational definition for the differentiation of such neurogenic cell lines is often made based on the morphometric criterion of a neurite reaching a length greater than twice the maximum somatic diameter (Liu et al., 2007). Based on this criteria, LKE-treated, FCS-replete NSC-34 cells generated multiple long, axon-like neuritic processes at approximately thrice the rate of LKE-untreated cells ( $p<0.01$ by two-tailed $t$ test) (supplemental Fig. 3 , available at www.jneurosci.org as supplemental material).

\section{Discussion}

Lanthionine metabolites represent a challenge to neurochemistry research. It is not known whether these compounds are waste or purposeful molecules. One thioether, cystathionine, is crucial to the consumption of hCys and regeneration of Cys. Failure to make cystathionine through mutation of cystathionine $\beta$-synthase $(\mathrm{C} \beta \mathrm{S})$ results in buildup of hCys, diminution of GSH, and advent 
of cardiovascular disease in transgenic mice (Watanabe et al., 1995; Wang et al., 2003; Kamath et al., 2006). Lanthionine differs from cystathionine in only one methylene group and forms from an alternative but scarcely investigated $C \beta S$-catalyzed reaction of Cys and Ser (Braunstein and Goryachenkova, 1984; Cooper and Anders, 1990; Cavallini et al., 1991; Cooper, 2004). Thus, Lan and its downstream metabolites may have functions yet to be discovered.

The biochemical origin of Lan is subject to debate, as is its fate. One pathway for Lan metabolism is via transamination with an $\alpha$-keto acid substrate in a reaction catalyzed by GTK (Cooper and Anders, 1990; Cavallini et al., 1991; Cooper, 2004). Kynurenine aminotransferase (KAT) is a multifunctional enzyme best known for synthesizing kynurenic acid (KYNA) from pyruvate and kynurenine (Cavallini et al., 1991; Cooper, 2004). KYNA is the only known endogenous glutamatergic antagonist, acting through an allosteric site on the NMDA receptor (Foster et al., 1992; Moroni, 1999; Urenjak and Obrenovitch, 2000). It is plausible that analogous KAT-formed sulfurous metabolites, such as LK, might serve functions in glutaminergic/GABAergic circuits analogous to those of KYNA or could serve other, unique functions. Elucidation of such possible functions would require identification of LK binding partners.

The present study identifies brain proteins that reversibly bind immobilized LK. Such proteins could represent sources for lanthionyl compounds, enzymes that convert these molecules, or effector proteins whose action is regulated by them. Among the LK-interacting proteins were several species associated with neurodisease. Notably, soluble CRMP2 is decreased in the brains of humans suffering from mild cognitive impairment or early-stage $\mathrm{AD}$ (Owen et al., 2009) and is a component of AD-associated neurofibrillary tangles that is alternatively phosphorylated early in $\mathrm{AD}$ progression (Cole et al., 2007). Recently, Reed et al. (2009) found CRMP2 to be oxidized and modified by the lipid oxidation product 4-hydroxynonenal in incipient $\mathrm{AD}$, a phenomenon that these researchers implicate in AD-associated neuritic dystrophy. CRMP2 interacts with cytoskeletal proteins to mediate signals related to neurite outgrowth and retraction, processes that may well be perturbed in AD (Owen et al., 2009). Polymorphisms in the CRMP2 promoter have been associated with paranoid schizophrenia, suggesting that CRMP2 may be important to mental health (Nakata et al., 2003). Recently, the anticonvulsive drug lacosamide (VimPat) was found to bind with CRMP2 (Beyreuther et al., 2007), suggesting pharmacological importance of CRMP2-binding small molecules to epileptiform pathologies.

The LK affinity experiment notably identified LanCL1 as an interaction partner. LanCL1 is a mammalian homolog of prokaryotic lanthionine cyclase (LanC) (Chatterjee et al., 2005; Willey and van der Donk, 2007). LanC catalyzes intramolecular thioether bond formation between Cys and dehydrated Ser or Thr residues, producing potent antibiotic peptides called "lantibiotics" (Chatterjee et al., 2005; Willey and van der Donk, 2007). Despite a similarity of nomenclature, mammalian LanCL1 may be only trivially related to bacterial LanC. LanCL1 does have significant primary sequence homology to LanCs, with a highly conserved $\mathrm{Zn}^{2+}$-containing putative active site (Chung et al., 2007; Zhang et al., 2009). Our laboratory first reported that mammalian brain LanCL1 binds GSH and oxidized glutathione with high affinity, suggesting phylogenetic conservation of sulfur enzymology (Chung et al., 2007). We subsequently obtained the first co-crystal structure of LanCL1 bound to GSH (Zhang et al., 2009) and showed that eukaryotic LanCL1 has an Src homology 3 (SH3) domain-interacting domain that binds Eps8 such that do- main mutants of LanCL1 disrupt nerve growth factor-mediated neurite extension in PC-12 cells (Zhang et al., 2009). To date, there have been no catalyses associated with LanCL1. The discovery in that LanCL1 binds LK in an unbiased, brain proteomewide affinity screen strongly suggests that mammalian LanCL1 does interact with lanthionyl metabolites, thereby strengthening the argument in favor of a functional role for LanCL1 in brain sulfur chemistry. These new findings strongly suggest that the relationship between LK and LanCL1 is not likely a mere accident of nomenclature.

Our study did not note LK interaction with LanCL2, which has come under study recently as a target for abscisic acid signaling of granulocyte exocytosis (Sturla et al., 2009); however, our brain protein extraction techniques could have failed to dissociate myristoylated LanCL2 from plasma membranes. Also, LanCL2 is less highly expressed in mammalian brain than LanCL1 (Chung et al., 2007), further diminishing the likelihood of capture on the LK column.

Nascent research may be pointing toward LanCL1 associations with disparate neuropathologies. The genomic region of human chromosome 2 q34 proximal to LanCL1 has been implicated in early-onset AD susceptibility (Scott et al., 2003), forms of familial schizophrenia (Aberg et al., 2008), and neural tube defects (Stamm et al., 2008). Several previous, separate associations of schizophrenia with CRMP2, STXBP1, and the LanCL1containing region of chromosome $2 \mathrm{q} 34$ offer an intriguing coincidence among these three candidate LK-binding proteins that is worthy of additional inquiry. It is plausible that molecules that affect neuron morphology, vesicle trafficking, or microglial activation might impact the structure and function of behavioral circuits that are perturbed in behavioral disorders. Future biochemical, proteomic, and genomic studies might therefore consider LanCL1 and Lan metabolites as speculative but plausible candidate molecules for risk associations with neurodisease.

Regarding possible functional commonalities, a number of the candidate LK binders are involved in axon myelination, growth cone guidance, or membrane trafficking and fusion. For example, CRMP2, STXBP1, and actin are dynamically involved with axon growth cone growth, collapse, and neuron arborization (Charrier et al., 2003; Arimura et al., 2004; Quach et al., 2004; Hikita et al., 2009). As noted above, LanCL1 may interact with growth factor pathways via SH3 domain-dependent binding modes to influence cellular differentiation and neuron morphogenesis (Zhang et al., 2009). Membrane-associated STXBP1 is widely appreciated for its role in vesicle docking during neurotransmitter release, binds the schizophrenia-associated protein dysbindin (Hikita et al., 2009), and may be decreased in the prefrontal cortex of persons suffering from schizophrenia (Kim et al., 2006; Behan et al., 2009). Curiously, LanCL1 has emerged independently in proteomic investigations of vesicle trafficking during Plasmodium infection of erythrocytes, wherein LanCL1 binds the vesicle secretion-directing plasmodium protein PFSBP1 (Blisnick et al., 2005). Thus, future studies of lanthionines and LanCL1 should consider whether neural membrane dynamics or trafficking might be LK sensitive or LanCL1 dependent.

Finally, this study is the first of which we are aware that reports specific cellular bioactivities inherent to a particular thioether ketimine. The mechanism(s) for microglial antagonism and neuronal effects remain to be determined; however, the effect of LKE on NSC-34 cell morphology is consistent with a functional interaction between LK and CRMP2 or factors upstream from CRMP2 such as small GTPases that have been implicated in CRMP2 function (Liu et al., 2007). CRMP2 is expressed in neu- 
rites and axon growth cones during nervous system development but also is expressed in oligodendrocytes and in subpopulations of neurons in the developed brain (Charrier et al., 2003). CRMP2 binds tubulin heterodimers but less avidly to polymerized microtubules, regulating microtubule dynamics in a poorly understood process that is subject to multiple levels of control through CRMP2 posttranslational modifications, including complex phosphorylations, glycosylation, and oxidative adduction (for review, see Charrier et al., 2003; Arimura et al., 2004; Reed et al., 2009). Thus, CRMP2 acts to transduce neural guidance signals, regulate axon length and neuritic arborization, and mediate axonal/dendritic fate (Charrier et al., 2003; Arimura et al., 2004; Quach et al., 2004). Lysophosphatidic acid induces cone collapse and neurite retraction by promoting CRMP2 phosphorylation in dorsal root ganglia (Arimura et al., 2000), but metabolites with the opposite effect have not been reported. Data presented herein suggests that LK may act as a positive rather than negative regulator of CRMP2-dependent neurite stability. The apparent disparity between our immunoprecipitation experiment and the NSC-34 cell culture actions of LKE may be partly resolved by supposing that LK may not decrease CRMP2:tubulin affinity so much as it may affect the conformation or composition of CRMP2-containing protein complexes, in a manner that could obscure the CRMP2 epitope recognized by anti-CRMP2, thus effectively removing a fraction of the CRMP2:tubulin pool that was probed in the IP experiment. The LK-promoted increase in CRMP2 binding to the tumor suppressing NF1 encourages additional research into possible oncological utilities of LK derivatives.

The anti-neuroinflammatory activity, neuroprotective and morphogenic potential inherent to LK may begin to suggest that certain lanthionine family members could be purposeful neurochemicals, such that appropriately bioavailable synthetic derivatives or precursor molecules might be exploited for therapeutic benefit against certain neurological diseases or injuries. Research is underway in our laboratory to explore such possibilities.

\section{References}

Aberg K, Axelsson E, Saetre P, Jiang L, Wetterberg L, Pettersson U, Lindholm E, Jazin E (2008) Support for schizophrenia susceptibility locus on chromosome 2q detected in a Swedish isolate using a dense map of microsatellites and SNPs. Am J Med Genet B Neuropsychiatr Genet 147B:1238-1244.

Arimura N, Inagaki N, Chihara K, Menager C, Nakamura N, Iwamatsu A (2000) Phosphorylation of CRMP-2 by Rho kinase: evidence for two separate signaling pathways for growth cone collapse. J Biol Chem 275: 23,973- 23:980.

Arimura N, Menager C, Fukata Y, Kaibuchi K (2004) Role of CRMP-2 in neuronal polarity. J Neurobiol 58:34-47.

Behan AT, Byrne C, Dunn MJ, Cagney G, Cotter DR (2009) Proteomic analysis of membrane microdomain-associated proteins in the dorsolateral prefrontal cortex in schizophrenia and bipolar disorder reveals alterations in LAMP, STXBP1 and BASP1 protein expression. Mol Psychiatry 14:601-613.

Beyreuther BK, Freitag J, Heers C, Krebsfänger N, Scharfenecker U, Stöhr T (2007) Lacosamide: a review of preclinical properties. CNS Drug Rev 13:21-42.

Blisnick T, Vincensini L, Barale JC, Namane A, Braun Breton C (2005) LANCL1, an erythrocyte protein recruited to the Maurer's clefts during Plasmodium falciparum development. Mol Biochem Parasitol 141:39-47.

Braunstein AE, Goryachenkova EV (1984) The beta-replacementspecific pyridoxal-P-dependent lyases. Adv Enzymol Relat Areas Mol Biol 56:1-89.

Broch OJ, Ueland PM (1984) Regional distribution of homocysteine in the mammalian brain. J Neurochem 43:1755-1757.

Cavallini D, Ricci G, Federii G (1983) The ketimine derivatives of thialysine, lanthionine, cystathionine, cysteine: preparation and proper- ties. In: Sulfur amino acids: biochemical and clinical aspects, pp 355-364. New York: Liss.

Cavallini D, Ricci G, Duprè S, Pecci L, Costa M, Matarese RM, Pensa B, Antonucci A, Solinas SP, Fontana M (1991) Sulfur-containing cyclic ketimines and imino acids. A novel family of endogenous products in search for a role. Eur J Biochem 202:217-223.

Charrier E, Reibel S, Rogemond V, Aguera M, Thomasset N, Honnorat J (2003) Collapsin response mediator proteins (CRMPs): involvement in nervous system development and adult neurodegenerative disorders. Mol Neurobiol 28:51-64.

Chatterjee C, Paul M, Xie L, van der Donk WA (2005) Biosynthesis and mode of action of lantibiotics. Chem Rev 105:633-684.

Chung CH, Kurien BT, Mehta P, Mhatre M, Mou S, Pye QN, Stewart C, West M, Williamson KS, Post J, Liu L, Wang R, Hensley K (2007) Identification of lanthionine synthase $\mathrm{C}$-like protein- 1 as a prominent glutathione binding protein expressed in the mammalian central nervous system. Biochemistry 46:3262-3269.

Cole AR, Noble W, van Aalten L, Plattner F, Meimaridou R, Hogan D, Taylor M, LaFrancois J, Gunn-Moore F, Verkhratsky A, Oddo S, LaFerla F, Giese KP, Dineley KT, Duff K, Richardson JC, Yan SD, Hanger DP, Allan SM, Sutherland C (2007) Collapsin response mediator protein-2 hyperphosphorylation is an early event in Alzheimer's disease progression. J Neurochem 103:1132-1144.

Cooper AJ, Anders MW (1990) Glutamine transaminase K and cysteine conjugate $\beta$-lyase. Ann NY Acad Sci 585:118-127.

Cooper AJL (2004) The role of glutamine transaminase K (GTK) in sulfur and alpha-keto acid metabolism in the brain, and in the possible bioactivation of neurotoxicants. Neurochem Int 44:557-577.

Duprè S (2000) Professor Doriano Cavallini: a life for sulfur biochemistry. Adv Exp Med Biol 483:27-29.

Durham HD, Dahrouge S, Cashman NR (1993) Evaluation of the spinal cord X neuroblastoma hybrid cell line NSC-34 as a model for neurotoxicity testing. Neurotoxicology 14:387-395.

Fontana M, Ricci G, Solinas SP, Antonucci A, Serao I, Duprè S, Cavallini D (1990) $\left[{ }^{35} \mathrm{~S}\right]$ Lanthionine ketimine binding to bovine brain membranes. Biochem Biophys Res Commun 171:480-486.

Fontana M, Brunori A, Costa M, Antonucci A (1997) Detection of cystathionine ketimine and lanthionine ketimine in human brain. Neurochem Res 22:821-844.

Foster AC, Kemp JA, Leeson PD, Grimwood S, Donald AE, Marshall GR, Priestley T, Smith JD, Carling RW (1992) Kynurenic acid analogs with improved affinity and selectivity for the glycine site at the $N$-methyl-Daspartate receptor from rat brain. Mol Pharmacol 41:914-922.

Gharib A, Sarda N, Chabannes B, Cronenberger L, Pacheco H (1982) The regional concentrations of $S$-adenosyl-L-methionine, $S$-adenosyl-Lhomocysteine, and adenosine in rat brain. J Neurochem 38:810-815.

Hensley K, Fedynyshyn J, Ferrell S, Floyd RA, Gordon B, Grammas P, Hamdheydari L, Mhatre MC, Mou S, Pye QN, Stewart C, West M, West S, Williamson KS (2003) Message and protein level elevation of tumor necrosis factor alpha $(\mathrm{TNF} \alpha)$ and $\mathrm{TNF} \alpha$-modulating cytokines in spinal cords of the G93A-SOD1 mouse model for amyotrophic lateral sclerosis. Neurobiol Dis 14:74-80.

Hikita T, Taya S, Fujino Y, Taneichi-Kuroda S, Ohta K, Tsuboi D, Shinoda T, Kuroda K, Funahashi Y, Uraguchi-Asaki J, Hashimoto R, Kaibuchi K (2009) Proteomic analysis reveals novel binding partners of dysbindin, a schizophrenia-related protein. J Neurochem 110:1567-1574.

Husi H, Grant SGN (2001) Isolation of 2000-kDa complexes of N-methylD-aspartate receptor and postsynaptic density 95 from mouse brain. J Neurochem 77:281-291.

Kamath AF, Chauhan AK, Kisucka J, Dole VS, Loscalzo J, Handy DE, Wagner DD (2006) Elevated levels of homocysteine compromise blood brain barrier integrity in mice. Blood 107:591-593.

Kim BU, Choi J, Ahn KH, Jeong JK, Ha CM, Jeong CS, Lee CK, Kang SG, Lee BJ (2006) Munc18 plays an important role in the regulation of glutamate release during female puberty onset. Mol Cells 22:30-35.

Li X, Higashikubo R, Taylor JS (2008) Use of multiple carboxylates to increase intracellular retention of fluorescent probes following release from cell penetrating fluorogenic conjugates. Bioconjug Chem 19:50-56.

Lin YL, Hsueh YP (2008) Neurofibromin interacts with CRMP-2 and CRMP-4 in rat brain. Biochem Biophys Res Commun 369:747-752.

Liu J, Lamb D, Chou MM, Liu YJ, Li G (2007) Nerve growth factor- 
mediated neurite outgrowth via regulation of Rab5. Mol Biol Cell 18: $1375-1384$

Marzinzig M, Nussler AK, Stadler J, Marzinzig E, Barthlen W, Nussler NC, Beger HG, Morris SM Jr, Brückner UB (1997) Improved methods to measure end products of nitric oxide in biological fluids: nitrite, nitrate and S-nitrosothiols. Nitric Oxide 1:177-189.

Moroni F (1999) Tryptophan metabolism and brain function: Focus on kynurenine and other indole metabolites. Eur J Pharmacol 375:87-100.

Nakata K, Ujike H, Sakai A, Takaki M, Imamura T, Tanaka Y, Kuroda S (2003) The human dihydropyrimidinase-related protein 2 gene on chromosome $8 \mathrm{p} 21$ is associated with paranoid-type schizophrenia. Biol Psychiatry 53:571-576.

Owen JB, Di Domenico F, Sultana R, Perluigi M, Cini C, Pierce WM, Butterfield DA (2009) Proteomics-determined differences in the concanavalin-Afractionated proteome of hippocampus and inferior parietal lobule in subjects with Alzheimer's disease and mild cognitive impairment: implications for progression of AD. J Proteome Res 8:471-482.

Quach TT, Duchemin AM, Rogemond V, Aguera M, Honnorat J, Belin MF, Kolattukudy PE (2004) Involvement of collapsing response mediator proteins in the neurite extension induced by neurotrophins in dorsal root ganglion neurons. Mol Cell Neurosci 25:433-443.

Reed TT, Pierce WM, Markesbery WR, Butterfield DA (2009) Proteomic identification of HNE-bound proteins in early Alzheimer disease: insights into the role of lipid peroxidation in the progression of $\mathrm{AD}$. Brain Res 1274:66-76.

Ricci G, Vesci L, Nardini M, Arduini A, Storto S, Rosato N, Cavallini D (1989) Detection of $2 \mathrm{H}$-1,4-thiazine-5,6-dihydro-3,5-dicarboxylic acid (lanthionine ketimine) in the bovine brain by a fluorometric assay. Biochim Biophys Acta 990:211-215.

Scott WK, Hauser ER, Schmechel DE, Welsh-Bohmer KA, Small GW, Roses AD, Saunders AM, Gilbert JR, Vance JM, Haines JL, PericakVance MA (2003) Ordered-subsets linkage analysis detects novel
Alzheimer disease loci on chromosomes 2q34 and 15q22. Am J Hum Genet 73:1041-1051.

Stamm DS, Siegel DG, Mehltretter L, Connelly JJ, Trott A, Ellis N, Zismann V, Stephan DA, George TM, Vekemans M, Ashley-Koch A, Gilbert JR, Gregory SG, Speer MC, NTD Collaborative Group (2008) Refinement of 2q and $7 p$ loci in a large multiplex NTD family. Birth Defects Res A Clin Mol Teratol 82:441-452.

Sturla L, Fresia C, Guida L, Bruzzone S, Scarfì S, Usai C, Fruscione F, Magnone M, Millo E, Basile G, Grozio A, Jacchetti E, Allegretti M, De Flora A, Zocchi E (2009) LanCL2 is necessary for abscisic acid binding and signaling in human granulocytes and in rat insulinoma cells. J Biol Chem 284:28045-28057.

Urenjak J, Obrenovitch TP (2000) Neuroprotective potency of kynurenic acid against excitotoxicity. NeuroReport 11:1341-1344.

Walker WS, Gatewood J, Olivas E, Askew D, Havenith CEG (1995) Mouse microglial cell lines differing in constitutive and interferon gammainducible antigen-presenting activities for naïve and memory CD4+ and CD8 + T cells. J Neuroimmunol 63:163-174.

Wang H, Jiang X, Yang F, Gaubatz JW, Ma L, Magera MJ, Yang X, Berger PB, Durante W, Pownall HJ, Schafer AI (2003) Hyperhomocysteinemia accelerates atherosclerosis in cystathionine beta: synthase and apolipoprotein $\mathrm{E}$ double knock-out mice with and without dietary perturbation. Blood 101:3901-3907.

Watanabe M, Osada J, Aratani Y, Kluckman K, Reddick R, Malinow MR, Maeda N (1995) Mice deficient in cystathionine beta synthase: animal models for mild and severe homocysteinemia. Proc Natl Acad Sci U S A 92:1585-1589.

Willey JM, van der Donk WA (2007) Lanthionines: peptides of diverse structure and function. Annu Rev Microbiol 61:477-501.

Zhang W, Wang L, Liu Y, Xu J, Zhu G, Cang H, Li X, Bartlam M, Hensley K, Li G, Rao Z, Zhang XC (2009) Structure of human lanthionine synthetase C-like protein 1 and its interaction with EPS8 and glutathione. Genes Dev 23:1387-1392. 